Utah State University

DigitalCommons@USU

Spring 2014

\title{
Herbivory strains resilience in drought-prone aspen landscapes of the western United States
}

Paul C. Rogers

Utah State University

Follow this and additional works at: https://digitalcommons.usu.edu/aspen_bib

Part of the Ecology and Evolutionary Biology Commons

\section{Recommended Citation}

published online at: http://onlinelibrary.wiley.com/journal/10.1111/\%28ISSN\%291654-1103

This Article is brought to you for free and open access by the Aspen Research at DigitalCommons@USU. It has been accepted for inclusion in Aspen Bibliography by an authorized administrator of DigitalCommons@USU. For more information, please contact

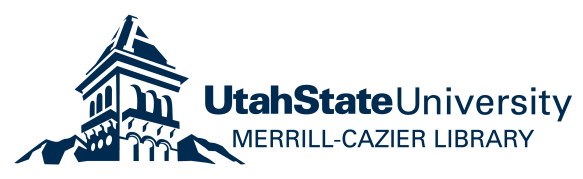


This is the pre-peer reviewed version of the following article:

Rogers, P. C.; C. M. Mittanck. 2013. Herbivory strains resilience in drought-prone aspen landscapes of the western United States. Journal of Vegetation Science In press.

which is being published online at: http://onlinelibrary.wiley.com/journal/10.1111/\%28ISSN\%291654-1103

\section{Ordinary Paper:}

\section{Herbivory strains resilience in drought-prone aspen landscapes of the western United States}

*Paul C. Rogers

Director, Western Aspen Alliance

Ecology Center

Utah State University

Ph: 1(435)797-0194

FAX: 1(435)797-3796

p.rogers@usu.edu Utah, USA 84322

Word count: 7,393 (inclusive of all text and references) 
Abstract

30 Aims: Aspen forests around the northern hemisphere provide rich biodiversity compared to surrounding

31 vegetation types. In both North America and Europe, however, aspen are threatened by a variety of

32 human impacts: clear-felling, land development, water diversions, fire suppression, and both wild and

33 domestic ungulate herbivory. We conducted a landscape assessment of quaking aspen (Populus

34 tremuloides) for the purpose of identifying key components of resilience. Specifically, we strove to test

35 novel measures linking plant-animal interactions, compare crucial functional differences in aspen types,

36 and make appropriate restorative recommendations based on the outcome of these assessments.

37 Location: The Book Cliffs region of eastern Utah and western Colorado, USA.

38 Methods: Seventy-seven one hectare plots were sampled for forest structure, composition, regeneration

39 and recruitment, landscape elements, browse level, and herbivore use. Use was determined by counting

40 the number of pellet groups by ungulate species at each sample location. We tested the efficacy of a

41 visual stand condition rating system when compared to objective metrics. A series of non-parametric

42 analyses were used to compare functional aspen types and stand condition groups by key variables.

43 Nonmetric multidimensional scaling (NMS) allowed us to explore all our data to find the most critical

44 measures of aspen stand conditions for the purpose of better informing future aspen monitoring.

45 Results: Results indicate that plots differed significantly by seral or stable aspen functional types, stand

46 condition rating, and browse species use. Ordination analysis revealed that regeneration level and

47 herbivore use were the strongest objective indicators of aspen stand conditions, while the stand condition

48 rating proved a valuable subjective index of forest status. While ungulate herbivory of aspen is

49 problematic internationally, our results show acute impacts where moderate slopes, relatively low water

50 availability, and intense browsing predominate.

51 Conclusions: Appropriate measures of aspen communities, informed by crucial functional divisions, have

52 allowed us to gain a clear understanding of conditions across this large landscape. Overall, aspen in our

53 study landscape is highly vulnerable to collapse due to narrow physiographic and climate limitations and 
54 browse levels. Without herbivory reduction, future conservation in such areas will be strained and 55 widespread system failure may occur.

56

57 Keywords: Populus tremuloides; ungulates; elk; deer; livestock; forest ecology; conservation;

58 biodiversity; climate; ordination

59 Nomenclature: Plant species follow Welsh et al., (1987). Mammal taxonomy is derived from (Zeveloff $60 \&$ Collett, 1988).

61 Abbreviations: NMS = Nonmetric multidimensional scaling; NAIP = National Agriculture Imagery

62 Program; SNOTEL = "snow telemetry" - a network of remote stations to gather and record snow water 63 content, precipitation, and air temperature data.

64 Running Head: Aspen, ungulates, and forest resilience 


\section{Introduction}

Aspen forests of the northern hemisphere provide unique resources where they are often the lone deciduous component of vast coniferous expanses. In both North America and Europe aspen are valued for their rich flora and fauna (Edenius \& Ericsson 2007; Kuhn et al. 2011). These biodiverse communities, however, are regionally threatened by management practices, such as logging and fire suppression which favor conifers, and by overabundance of either domestic or wild herbivores (Kota \& Bartos 2010; Edenius et al. 2011). While many of the underlying issues facing quaking aspen (Populus tremuloides $)$ and European aspen (P. tremula) are similar, there are two notable differences: quaking aspen tend to form large contiguous stands and, particularly in western locales, they occur in relatively drier climates. Climate thus becomes a key component of future quaking aspen management where it is thought that these forests are at or near their moisture resource margins (Rehfeldt et al. 2009; Martin \& Maron 2012). Stressors on aspen landscapes that augment climate impacts, therefore, are of high concern to those addressing forest system resilience.

In western North American there are numerous recent studies documenting both declines (Di Orio et al. 2005; Worrall et al. 2008) and expansions (Manier \& Laven 2002; Kulakowski et al. 2004) of aspen forests. These works document cover change at a variety of spatial and temporal scales, therefore it is difficult to make direct comparisons between results. Moreover, recent authors have pointed out distinct aspen functional types (Shepperd et al. 2006; Rogers et al. 2013) which would be expected to respond differently to short- and long-term perturbations. Aspen cover change has been attributed to fire suppression and conifer encroachment, past logging, climate variability, settlement period burning, and browsing by wild and domestic ungulates (Kulakowski et al. 2004; Shepperd et al. 2006; Rogers et al. 2011). Some results have indicated positive and negative cover change within the same landscape (Kulakowski et al. 2004; Sankey 2009), lending further support to the concept of varying aspen functional types (Rogers et al. 2013). Given that aspen forests have undergone modest-to-large change over the past 150 years - often where human actions combine with stochastic disturbances — practitioners have become concerned about the future of these forests under current management regimes. Contemporary thinking 
91 holds that "managing for resilience" will afford the best hopes for sustainable quaking aspen (as in most 92 systems). Forest managers are therefore interested in sustaining or creating resilient aspen communities 93 with a foundation of state-of-the-science knowledge and adaptive practices. Where plant-animal

94 interactions are paramount, a barrier to such goals has been a lack of effective communication between 95 federal forest and state wildlife practitioners in both scientific and applied realms.

96 While aspen is highly valued for its' biodiversity, in some locales herbivores are having undue

97 impact on the ability of these systems to maintain ecosystem functions. Aspen shoots and leaves provide

98 valuable nutrition to several species, especially early and late in the growing season when diversity of

99 browse is limited (Jones et al. 2005; Beck et al. 2006). In Scandinavia, moose (Alces alces) are the

100 primary herbivore affecting aspen recruitment (Edenius \& Ericsson 2007; Edenius et al. 2011). In the

101 western United States browsing cattle (Bos spp.), sheep (Ovis spp.), North American elk (Cervus

102 elaphus), and mule deer (Odocoileus hemionus) in many areas are severely inhibiting stand renewal via

103 repeated aspen sprout consumption (DeByle 1985; Zeigenfuss et al. 2008; DeRose \& Long 2010; Rogers

104 et al. 2010). This phenomenon seems particularly acute where wild elk populations are thought to be

105 beyond "historical range of variation" levels due to aggressive reintroduction programs (e.g., Bailey et al.

106 2007; Stritar et al. 2010) and relatively low levels of predation (Beschta \& Ripple 2009). Though reduced

107 elk numbers from wolf predation may lead to successful aspen recruitment (Fortin et al. 2005), there is

108 some dispute over whether commensurate alterations of browsing patterns wrought by fear of predation

109 are further influencing regeneration success (Kauffman et al. 2010). In most of the western U.S.,

110 however, significant predation of wild and domestic ungulates is absent as recent reintroductions of a

111 critical carnivore, the gray wolf (Canis lupus), are limited to specific geographic zones. Cougar (Felis

112 concolor) apparently do prey on younger or smaller elk, though their primary ungulate prey appear to be

113 adult mule deer (Matson et al. 2007). Overall, the impact of large herbivores on aspen communities may

114 be reduced to three key factors: nutrition, population, and frequency of movement. Browsers who require

115 specific nutrient content of aspen leaves or bark (continuously or seasonally) and who are present in large 
numbers for extended periods may reduce long-term system resilience (Beck et al. 2006; Martin \& Maron

117 2012). Presence of multiple aspen-browsing species will only amplify this phenomenon.

118 We undertook a landscape-level survey of aspen condition and resilience in a remote portion of 119 the American West known as the Book Cliffs. As a relatively short-lived clonal species aspen is highly

120 dependent on both continuous and episodic recruitment (Kurzel, et al. 2007). Accordingly, a large part of

121 our monitoring effort would rely on cataloguing the status of this "next generation" component of these

122 forests. With this in mind, the current study has three prime objectives: 1) to conduct a defensible

123 landscape assessment of aspen status across the Book Cliffs, while testing new measures for linking

124 animal impact to stand conditions; 2) to understand distinct aspen types and determine environmental

125 conditions which differ among these groups; 3) to make appropriate restorative recommendations for

126 aspen systems based on outcomes of the first two objectives. Findings from this work will have

127 ramifications for large portions of western North America, and more broadly in northern Europe, where

128 issues of large ungulate-aspen browsing are rife within conservation circles.

Methods

Study Area

The Book Cliffs is part of a larger 230-km long feature known as the Tavaputs Plateau, which is

134 bisected by the Utah-Colorado border in the western United States (Figure 1). This arid plateau slopes 135 gently northward to the Uintah Basin and drops abruptly to the south into Utah's Canyonlands region of 136 the Colorado Plateau (Sexton et al. 2006). The area consists of plateau tops dissected by steep valleys.

137 Soils are derived predominantly from sandstone and shale substrates, resulting in rocky-to-sandy loams in 138 much of the range. The elevation zone where aspen occurs, between 2,075 to 2,611 m, is fairly narrow 139 compared to other landscape-level assessments regionally (Kurzel et al. 2007; Rogers and Ryel 2008), 140 suggesting that environmental conditions, particularly precipitation, are limiting to aspen occupancy

141 (Mittanck 2012). A weather monitoring station located in the aspen zone of our study area (SNOTEL site 

\#461) recorded an average annual precipitation of $542 \mathrm{~mm}(\mathrm{SD} \pm 127)$ between 1987-2012. Aspen and conifer stands are bounded by sagebrush (Artemesia spp.) on adjacent dry sites and, as elevation decreases, pinyon (Pinus edulis) and juniper (Juniperus osteosperma, J. scopulorum) woodlands. Our study area consists of 268 distinct aspen polygons scattered across $\sim 18000$ ha of the Book Cliffs in Utah and Colorado. Polygons were identified using three bands, including near-infrared, of National Agriculture Imagery Program (NAIP) imagery. Images were enhanced to allow a linear stretch across three standard deviations of the spectral data. This process increases contrast between vegetation types allowing easier interpretation. An earlier aspen stand assessment in this same area yielded a photo interpretation accuracy level of $88 \%$ (Mittanck 2012). The primary criterion used to delineate aspen polygons was if the area was contiguously forested with an aspen component. Polygons greater than 50\% aspen cover and more than 0.5 ha were randomly selected for sampling. The completed procedure resulted in an initial selection of 100 sample polygons, of which 77 were field sampled (Figure 1). (Sixteen polygons were inaccurately identified as meeting our species/cover criteria and seven were eliminated due to access and time constraints.) Average sampled polygon size equaled 3.5 ha (range 0.531 ha). In sum, we sampled $29 \%$ of the total polygon population (representing $34 \%$ of aspen area) within the study area, enabling us to make strong inferences about the overall Book Cliffs aspen landscape.

\section{Field Methods}

The prime sample unit for this study consists of a ha ${ }^{-1}$ area, henceforth called the "plot," at the centroid of each polygon. Plots were sampled only if they were at least $50 \%$ aspen cover and entirely within a forested area. Certainly variation was encountered in aspen polygon conditions. However, with the above requirements—along with the random polygon selection and systematic centroid location—plot data are assumed to represent mean conditions for each polygon. At each plot, visual estimates of aspen and conifer cover were made for the entire polygon with the aid of aerial photos. A walk through the ha ${ }^{-1}$ sample area was made to gain an overall rating of stand conditions using criteria defined in Table 1, an estimate of discrete vertical "layers" of aspen, and the dominant understory cover by plant group (i.e., 
shrub, trees, grasses, forbs). Each plot was assigned an aspen stand type, either seral or stable (Harniss \&

169 Harper 1982). We define seral aspen as containing more than $10 \%$ conifer cover or, if stand-replacing

170 disturbance such as fire or logging occurred within the past three decades, the potential to exceed this

171 cover. Stable aspen implies $<10 \%$ conifer cover and long-term "stability" in a single species state (i.e., $\geq$

172100 years). In most instances the distinction between seral and stable plots is immediately evident as

173 there are either no conifers or many conifers within an aspen forest. Geographic coordinates were

174 obtained and four plot photos were taken to document understorey composition and structure.

175 At each plot center, two perpendicular $30 \times 2 \mathrm{~m}$ transects were established and the following

176 field measures were taken: percent aspen, conifer, and sagebrush cover; regeneration $(<2 \mathrm{~m}$ height $)$,

177 recruitment ( $\geq 2 \mathrm{~m}$ height, $<8 \mathrm{~cm}$ diameter breast height [dbh]), and mature tree $(\geq 8 \mathrm{~cm} \mathrm{dbh})$ counts by

178 species; mature tree counts by three diameter classes $(8-15 \mathrm{~cm} ; 16-25 \mathrm{~cm} ;>25 \mathrm{~cm} \mathrm{dbh})$; and fecal pellet

179 counts by groups (deer and elk) and individual feces (cattle). Pellet groups were defined as any

180 assemblage of feces consisting of three or more pellets from the same defecation (Bunnefeld et al, 2006).

181 Pellet groups give relative frequency of species' visits (use) of aspen stands; they are not direct measures

182 of browse intensity. Two mature representative, healthy, aspen and two conifer (if present) were aged at

183 breast height to determine overall stand age. Finally, field personnel recorded recent disturbances, if

184 applicable, across the sample $\mathrm{ha}^{-1}$. All transect data were expanded to represent conditions on a ha ${ }^{-1}$ basis $^{\text {is }}$

185 for analytical purposes.

186

\section{Analytical Methods}

188 Analytical efforts for this work were exploratory in nature, meaning our intent was to determine

189 the most important measures among a suite of environmental variables. First, we wished to combine

190 proven aspen landscape survey methods (Rogers et al. 2010) with experimental techniques designed to

191 simplify monitoring methods for future work. Thus, we were in search of key metrics, or "indicators," of

192 aspen conditions. Two non-parametric tests were used to address indicators individually. The two-sided

193 Wilcoxon-Mann-Whitney U test was used to evaluate field variables for differences between seral and 
194 stable aspen stands to establish whether such a delineation was ecologically meaningful. The Kruskal-

195 Wallace test, a non-parametric equivalent to analysis of variance, was the primary means of assessing the 196 usefulness of the stand condition ranking. Direct measures of aspen mortality, condition and amount of 197 regeneration and recruitment, and level of browsing (Table 1) were not considered independent of stand 198 condition, therefore they were removed from these tests of group differences. We evaluated the

199 remaining field variables for group effects based on their overall rating of good, moderate, or poor stand 200 condition. The Kruskal-Wallace test does not provide a between-groups test of significance, thus further 201 evaluation of stand condition, as well as other field measures, would be addressed with a broader 202 statistical approach using the entire data set in distance matrix analyses.

203 Nonmetric multidimensional scaling (NMS) is an ordination technique that provides a robust 204 method of understanding salient structure within ecological data sets which are expected to be nonnormal 205 and discontinuous in their nature (McCune et al. 2002). Our goal in using NMS was to seek out critical 206 measures of aspen stand conditions within our data set to provide a basis for evaluating the entire Book

207 Cliffs landscape. The wide variation in data types (e.g., counts, ratings, digitally generated location data, 208 measures, cover estimates) required a flexible and defensible analytical approach such as NMS (Peck 209 2010). Twenty-three plot-level variables (Table 2) found on the 77 sample plots within our study area 210 formed the primary matrix in our NMS analysis. An initial outlier analysis was performed to check of 211 data anomalies based on two standard deviations of the Sørensen distance measure (Peck 2010). No data 212 transformations were required for this analysis. We used the PC-ORD software to conduct NMS and 213 produce related graphic outputs (McCune \& Mefford 2006). The ordination was initiated with a random 214 start number upon 250 runs of the actual data set using Sørensen distance measure. We assessed final 215 NMS solution dimensionality by plotting stress as a function of number of dimensions or axes. Where 216 two consecutive dimensions were $\leq 5$ points of stress apart the lower dimension was selected as our 217 optimum solution (McCune et al. 2002). A Monte Carlo test was then run on the lowest stress solution 218 using 250 randomized runs to evaluate the probability of our result being greater than chance occurrence. 
219 For all analyses in this study results were considered significant when reaching the $95 \%$ confidence 220 interval (i.e., $p$-value $\leq 0.05$ ).

222 Results third were seral to conifer species. No plots in our survey sampled stand-replacing disturbance, though significant "browsing" or "grazing" were noted on $16 \%$ of stands. We found several significant differences in environmental variables by these two primary aspen stand types (Fig. 2). Overall, stable greater regeneration $(\mathrm{Z}=-2.95 ; p=0.003)$, and more trees $\mathrm{ha}^{-1}(\mathrm{Z}=-2.21 ; p=0.027)$. We found no statistical difference in recruitment levels between stand types. Seral aspen in the Book Cliffs were significantly older than stable aspen forests $(Z=2.09 ; p=0.039)$. Stable stands are experiencing heavier

232 levels of browse $(Z=-2.21 ; p=0.038$; box plot not shown $)$ which likely relates to higher scat counts among cattle $(Z=-3.85 ; p<0.001)$, elk $(Z=-3.59 ; p<0.001)$, and the total scat $(Z=-4.41 ; p<0.001)$.

234 Deer pellet counts were not significantly different between stand types $(Z=-1.13 ; p=0.257)$. Elk feces accounted for $67 \%$ of the total scat count, with cattle and deer at $22 \%$ and $11 \%$, respectively.

237 Only three of 77 sampled plots contained greater than 500 recruitment stems ha $^{-1}$, a suggested minimum 238 threshold for stand replacement (O'Brien et al. 2010). Given that many sample plots had fewer than 500 239 mature trees $\mathrm{ha}^{-1}$ we took a closer look at aspen recruitment based on local conditions. Using a more site240 driven approach, we calculated live recruitment as a percentage of total mature aspen trees ha ${ }^{-1}$ with the 241 logic that $100 \%$ would support complete immediate aspen stand replacement and 50\% ample recruitment 242 for gradual (i.e., gap-phase) replacement. Even this conservative consideration yielded very poor 243 recruitment across the Book Cliffs landscape (Fig. 3). Ninety-four percent of sample plots had a fewer 
244 than $50 \%$ recruitment based on total mature aspen trees ha ${ }^{-1}$. Fifty-five of the total 77 aspen stands had 245 zero recruitment.

In addition to a number of objective field-based metrics of aspen forest conditions, we tested the 247 efficacy of a subjective stand condition rating system. We found several significant group trends along 248 our stand condition continuum (Fig. 4). Aspen polygons in both poor and good condition were at higher 249 elevations than those with moderate visual impacts; stands in the worst condition were found at the 250 highest elevations $\left(\chi^{2}=7.62 ; p=0.019\right)$. As expected, as stands age their condition deteriorates $\left(\chi^{2}=\right.$ $2519.60 ; p=0.007)$. Basal area $\left(\chi^{2}=10.58 ; p=0.004\right)$ and trees $\mathrm{ha}^{-1}\left(\chi^{2}=20.15 ; p<0.001\right)$ decreased as 252 stands condition declines. As an indirect measure of browsing impact, there were significant increases in 253 elk scat $\left(\chi^{2}=20.09 ; p<0.001\right)$ and total scat $\left(\chi^{2}=17.68 ; p<0.001\right)$ as stand condition deteriorates.

254 Both cattle $\left(\chi^{2}=3.95 ; p=0.138\right)$ and deer $\left(\chi^{2}=4.59 ; p=0.106\right)$ failed to show significant relationships to stand condition. Overall, these data provide significant and visually compelling trends, but do not specify differences between each group. To pursue this further, we explored overall dataset structure using more 257 powerful analytical tools.

Nonmetric multidimensional scaling (NMS) provided a parsimonious method for exploring

259 distance relationships by ordination of all variables in "sample plot space." No data or plots were

260 eliminated in outlier analysis. NMS ordination produced a 2-dimensional (i.e., axes) solution with a final 261 stress of 12.03 (instability < 0.000). We assessed stability by plotting a graph of stress versus number of 262 iterations. Stability was reached at 54 iterations from a maximum of 500 runs of our "real" dataset. Monte 263 Carlo test results indicate that the two-axis solution using real data was significant $(p=0.004)$. Two axes 264 explain nearly all of variability in the Book Cliffs aspen dataset (Axis 1: $r^{2}=0.61$; Axis 2: $r^{2}=0.31$; total $265 r^{2}=0.92$, orthogonality $\left.=97.3 \%\right)$. Cumulatively, the degree of stability, randomization results, and 266 variability explained by the two-axis solution indicate a highly significant final NMS result (McCune et 267 al. 2002). An ordination joint plot and the categorical variable "stand condition class" were overlaid on 268 the results of the NMS (Fig. 5). Axis 1 strongly represents aspen regeneration $\mathrm{ha}^{-1}$ and to a lesser degree 
aspen recruitment. Axis 2 displays a robust alignment with overall scat ha ${ }^{-1}$, as well as to individual

270 browsing species; dominantly elk. All environmental variables are presented here in terms of Pearson's

271 coefficient $(r)$ values as they relate to the primary axes identified in NMS (Table 2).

273 Discussion

\section{Key aspen indicators inform resilience}

We set out to conduct a landscape assessment of aspen communities in the Book Cliffs of eastern

277 Utah. Our random sample of nearly one-third of all stands in the area showed an overall aspen population 278 under moderate to high threat. Stable aspen make up two-thirds of the Book Cliffs aspen landscape, thus 279 continuous recruitment is crucial to long-term forest vigor. Only $23 \%$ aspen polygons were rated as being

280 in good condition based on visual assessments of stand mortality, regeneration and recruitment, and

281 browse levels (Table 1). While $27 \%$ of sample sites contained minimum required regeneration levels, just

282 three of 77 stands contained adequate levels of recruitment (O'Brien et al. 2010). Whether aspen

283 produces many or few suckers over time is less important than survivorship above browse level. Once

284 above this height, understorey stems can eventually fill canopy gaps as the relatively short-lived canopy

285 trees die. Resilience to insects and disease, particularly in stable aspen, depends on a diverse height and

286 age profile (Worrall et al. 2010) and young stands (both seral and stable) dominated by aspen are less

287 prone to fire (Shinneman et al. 2013) thereby providing a buffer against stand collapse. In an effort to

288 gain appropriate measures of recruitment based on site-specific data, which include relatively low water

289 resource availability (Mittanck 2012), we looked at recruitment as a proportion of actual live mature

290 stems (Fig. 3). Even with this more conservative adjustment, landscape-level recruitment was very low

291 indicating a great majority of aspen stands with little resilience to future drought or disturbance.

292 Ordination of all physical, mensuration, browse, and scat data gives us a strong indication of what factors 293 are responsible for this poor level of aspen recruitment. 
295 problem for forest, range, and wildlife ecologists. Standard measures of animal and tree populations

296 occur at widely varying scales and browsers may not exhibit predictable movement and feeding patterns

297 from year to year. Moreover, in areas of limited predation and accessible aspen terrain the combined

298 effects of herbivory are severely limiting to aspen recruitment (Beschta \& Ripple 2010; Rogers et al.

299 2010). In the current work, we sampled scat on the same scale (i.e., transects) as forest structure data. To

300 our knowledge, this spatial symmetry has not been attempted elsewhere and may help overcome previous

301 barriers in understanding effects of widely roaming herbivores at stand-levels. Browse levels to

302 regeneration were moderate-to-high across most of the study area as reflected by a $51 \%$ average browse

303 level combined with very low levels of recruitment. Olmstead (1979) suggests that more than 30\% aspen

304 sucker utilization by elk lead to declines in stand density. Others suggest a more conservative guideline

305 where $>20 \%$ annual browse of aspen leaders will result in decreases in stand density (Jones et al. 2005).

306 Further connections between elk use, browse level, and recruitment success are presented for the Book

307 Cliffs landscape through ordination (Fig. 5; Table 2). In NMS analysis, Axis 1 positively represents

308 aspen regeneration, as well as moderate correspondence to recruitment and trees ha ${ }^{-1}$. Axis 2 relates most

309 strongly to elk scat counts, but also to deer and cattle scat. Additionally, axis 2 corresponds with percent

310 aspen canopy cover (negative to conifer cover) and heightened browse levels (Table 2). This indicates

311 greater impacts and use of stable aspen stands by all herbivores likely due to their generally moderate

312 terrain (Fig. 2). We should emphasize that while overall strong correspondence to regeneration and scat

313 counts in the ordination were exhibited, most physiographic indicators showed weak relationships to both

314 objective and subjective indices (Table 2). This poor showing of environmental variables may be further

315 indication that our landscape-level results from the NMS are not tied to specific locations, but rather to

316 other causal factors.

317 Our study used scat counts to represent herbivore use of aspen habitat and indirectly level of

318 aspen browse. Use of scat counts as surrogates for habitat use have been criticized by some (Smart et al.

319 2004), but favored by others when compared to animal radio-telemetry data (Borkowski 2004; Bunnefeld 
et al. 2006). The central advantage of the scat count method was a direct correspondence of site and scale

321 of sampling. Studies using radio-telemetry cannot be easily calibrated to our stand-level sample units and

322 thus would be very difficult to understand as we attempted to measure landscape conditions and habitat

323 use based on these $\mathrm{ha}^{-1}$ measures. A disadvantage when comparing between species is that each feces

324 occurrence cannot a priori be assumed to mean the same level of use. We feel, however, that nominal

325 differences between elk-two-thirds of all scat; $>3 \mathrm{x}$ cattle and $>5 \mathrm{x}$ deer-and other herbivore scat

326 counts provide proximate evidence for elk's primary role in limiting aspen recruitment on this landscape.

327 Ordination results (Fig. 5; Table 2) confirm a dominant role of elk among all herbivores and only elk and

328 total scat counts related significantly to our stand condition rating system (Fig. 4).

Our chief motivation for developing an aspen stand rating system was efficiency. Degraded

330 aspen communities in our region are commonplace (Binkley 2008; Worrall et al. 2008; Rogers et al,

331 2010), therefore a quick and credible means for managers to assess conditions across very large

332 landscapes is desirable. We pitted several objective measures of aspen systems against our subjective

333 stand condition and confirmed the utility of this measure as a surrogate for overall condition, as well as

334 aspen mortality, stand structure, regeneration/recruitment, browse, and (independently) animal use. We

335 consider the high correspondence to scat ha ${ }^{-1}$ (Fig. 5) an independent estimate of herbivore use, as there

336 are no direct elements of scat or animal visitation in our stand condition classes (Table 1). Where

337 resources are low and there is need for widespread aspen monitoring we suggest use of stand condition

338 ratings alongside key site measures, such as regeneration, recruitment, and browse counts, to glean

339 meaningful information with minimum expenditure.

\section{The role of functional aspen types in the Book Cliffs}

342 Before we can assess impacts on a particular system it is important to understand broad-scale

343 ecological divisions. Our initial findings showed two distinct aspen types occupying different realms of

344 key environmental variables (Fig. 2). This overall picture generally fits that of the Colorado Plateau

345 stable and montane seral functional types described by Rogers et al. (2013), although the Book Cliffs 
appear to be within the lowest elevation and precipitation niche for western aspen (Sexton et al. 2006;

347 Mittanck 2012). Within our study area, a novel finding is that seral aspen occupy relatively lower

348 elevations, unlike other locations where stable aspen is common on the Colorado Plateau (Rogers et al.

349 2010). We do find, however, that pure aspen types often occur on lower slope angles which make them

350 more vulnerable to herbivores (Harniss \& Harper 1982; Binkley 2008; Zegler et al. 2012 ). Our results

351 confirm use on lower angle slopes as heavier levels of elk and cattle occupancy occurred in stable aspen

352 forests (Fig. 2). An alternative explanation for greater herbivory in stable aspen may simply be greater

353 availability of young stems, as shown by the strong positive correlation of regeneration to stable aspen

354 (Fig. 2). It appears that deer use both seral and stable habitat equally, though at lower overall levels.

355 In terms of stand structure measures, we also found evidence of distinct functional groupings

356 between seral and stable aspen. Where aspen are seral to conifers, stands are generally older than pure

357 sites (Fig. 2; Rogers et al. 2010), although clear indication of stand age is sometimes difficult in healthy uneven-aged stable aspen. Seral stands in the Book Cliffs contained less mature aspen trees ha $^{-1}$ than the upland stable type. Greater aspen regeneration on upland stable sites corresponds to overall tree counts. Although there is more regeneration in stable forests, it appears an insignificant number of stems in either

361 functional category are surviving to a recruitment stage (Fig. 3). Thus, where healthy stable aspen

362 (particularly) should exhibit multiple stand layers (Harniss \& Harper 1982; Rogers et al., 2010; 2013), we

363 found only about one-third (35\%) of such vertically diverse locations in the Book Cliffs. The low overall

364 tally of recruitment (Fig. 3) amplifies the lack of vertical diversity and high level of concern at the

365 landscape-scale. Anecdotally, ungulate exclosures observed with the Book Cliffs demonstrate adequate 366 recruitment, even where deer are allowed access (supplemental photos online).

\section{Resilience, restoration, and monitoring of herbivore impacted aspen}

Consumption beyond replacement level of understory plants, and in particular juvenile trees, by

370 large herbivores is common globally (White et al. 1998; Gill 2006; Edenius \& Ericsson 2007; Takatsuki

371 2009; Tanentzap et al. 2009). In areas dominated by conifers (e.g., northern Europe, northern and western 
372 North America), aspen provide unique habitat and high levels of biodiversity (Kouki et al. 2004; Kuhn et 373 al. 2011). As a keystone species (Campbell \& Bartos 2001; Edenius et al. 2011), loss or reduction of 374 aspen communities has cascading effects on dependent biota (Bailey et al. 2007; Rogers \& Ryel 2008;

375 Kuhn et al. 2011) including target herbivores (Beck et al. 2006). In our study area in the arid western 376 United States we consider aspen forests, particularly stable stands, to be of relatively low resilience to 377 environmental changes due to low water availability and high accessibility provided by generally

378 moderate- to low-angle slopes (Fig. 2; Zegler et al. 2012). Mittanck (2012) found that the Book Cliffs 379 was the most arid of regions supporting an "aspen niche" among his four study sites spread across Utah.

380 A basic definition of ecological carrying capacity (Beck et al. 2006, p.283) simply states "an equilibrium

381 between populations of plants and herbivores in the absence of harvest." Evidence presented here

382 suggests that browsers, particularly elk, are beyond carrying capacity for the Book Cliffs aspen landscape 383 and are having long-term effects on this landscape. Potential for significant aspen cover loss is high with 384 consequent effects on dependent species. With continued heavy browsing, we should expect to see stand 385 decline and loss of entire age cohorts that coincide with noted increases in large herbivore populations (Binkley 2008; Beschta \& Ripple 2010). Furthermore, sites at lower elevations in accessible terrain may

387 be most vulnerable to predicted warming climates via reduced snow cover which carries the dual negative 388 impacts of decreased water resources and increased winter access by browsers (Martin \& Maron 2012). We recommend restoration of aspen forests based on appropriate aspen functional type (Rogers et

390 al. 2013). In the current work we have highlighted key environmental differences between seral and 391 stable aspen. With a view toward restoration, we favor emulating ecological processes that have shaped 392 these aspen systems for centuries. While seral aspen depends on irregular fire and other stand-replacing 393 disturbance, stable communities are driven by small group- and tree-level mortality and continuous or 394 episodic recruitment (Harniss \& Harper 1982; Kurzel et al. 2007). Thus, commonly prescribed burning or 395 clear-felling are in many cases appropriate for seral aspen and inappropriate for stable types. Once

396 browse pressure is removed, or reduced to a sustainable level, stable aspen often need little or no stimulus 397 to rejuvenate their stand structure. If herbivory cannot be curtailed stable stands will eventually die-off 
and seral stands may be overtopped by conifers. In fact, Edenius et al. (2007), working in European aspen $(P$. tremula), found that heavy browsing in the absence of disturbance-either human-caused or natural —will accelerate succession toward conifer dominance to the detriment of remaining mature

401 aspen. In smaller stands, or specific environmental situations (e.g., riparian or recreational locations), 402 aspen may be protected by temporary fencing from browsers. However, this protection strategy is not 403 feasible for large landscapes where fencing is cost prohibitive. Finally, we encourage allowance for 404 natural or prescribed burns to increase chances of genetic diversity through aspen seedling establishment 405 (Long \& Mock 2012). This strategy is more appropriate for seral types that burn more readily, than for 406 stable aspen that are generally not susceptible to fire (Shinneman et al. 2013). While it is now accepted that aspen establishment by seed is more common than previously thought (Long \& Mock 2012), we have 408 little understanding of mechanisms of occurrence in stable types where evidence suggests high genetic 409 diversity, too (Mock et al. 2008). Both seral and stable aspen will require significantly reduced browsing, thus elk population 411 reduction should be considered a core strategy where heavy browsing, such as in the Book Cliffs, can be 412 credibly documented (Seager et al. 2013). Current elk and livestock management in this area encourages 413 sustained or increased animal populations. We concur with Seager et al. (2013) that increased hunting 414 can and should be implemented where reintroduction of apex predators, such as wolves (Canis lupus), are 415 politically unfeasible. Secondarily, seral types may require complementary conifer disturbance to create 416 forest openings and facilitate both seedling and sucker regeneration (Long \& Mock 2012; Rogers et al. 417 2013).

418 Pre- and post-treatment monitoring using a scheme similar to the one tested here is required to 419 further understand if actions are having desired restorative effects. For example, use of fenced exclosures, 420 while appropriate for demonstrative purposes, raise concerns when prescribed as a landscape-level 421 management option. Past exclosure studies have shown that aspen will respond heartily to complete 422 protection (Kay \& Bartos 2000; Kay 2001). Monitoring within and outside exclosures will give reliable 423 measures of sprouting ability and no-browsing protection, respectively, but provide little useful 
424 information regarding reduced herbivory in the context of stand- or landscape-level aspen restoration.

425 For this reason, the current study area as well as locales with similar browse issues, will require

426 documentation of active (stimulus) and passive (reduction or removal of browsers) management effects.

427 While we fully expect confounding factors (i.e., climate, disturbance, human impacts), our overall

428 objective with monitoring and adaptive management is to facilitate future aspen community resilience. In

429 a setting such as the Book Cliffs that is predisposed to low resilience, restoration ecologists would do well

430 to focus resources toward increasing the systems' capacity to rebound under expected stresses.

432 Conclusions

Findings from the present study have conservation applications in drought-prone, drought expectant, and chronically browsed forest systems. The Book Cliffs aspen landscape constitutes a

436 relatively low elevation dry setting as compared to other locations around the region (Mueggler 1988;

437 Mittanck 2012) and therefore may be viewed as a harbinger of future climate conditions in other settings.

438 The narrow elevation and moisture band in which aspen exist here is thought to be vulnerable even in the 439 absence of heavy browse (Rehfeldt et al. 2009). Though there is an abundance of seral aspen at generally 440 lower elevations and on steeper slopes, the area is notable for its high presence of the single-species stable 441 type. We recommend future conservation that emulates the dynamics within these distinct functional 442 types. For example, while clear-felling or prescribed burning may fit seral types, they are inappropriate in 443 stable aspen (Shinneman et al, 2013; Rogers et al. 2013). Given that mature aspen are short-lived 444 compared to their conifer cohorts, aspen assessments must rely heavily on measures of regeneration and 445 recruitment. Recruitment is a key measure of system resilience where stand-replacing disturbance, 446 browsing pressure, and warming climates are expected to stress these systems. We suggest using 'natural 447 range of variation' to guide adaptive actions (Landres et al. 1999). Based on results presented here, there 448 is strong evidence of elk browsing being beyond sustainable levels for the aspen landscape in our study 
area. Similar conditions may be found in a broader swath of the Colorado Plateau region where stable aspen prevails (Rogers et al. 2010; Rogers et al. 2013).

\section{Acknowledgements}

agreement number L10AS00341. We would like to thank Dane Gyllenskog for field data collection. grateful to anonymous technical reviewers for their insightful suggestions. Discussions, conclusions, and recommendations are those of the authors and not sponsoring entities.

\section{References}

Bailey, J.K., Schweitzer, J.A., Rehill, B.J., Irschick, D.J., Whitham, T.G., \& Lindroth, R.L. 2007. Rapid shifts in the chemical composition of aspen forests: an introduced herbivore as an agent of natural selection. Biol. Invasions 9: 715-722.

Beck, J.L., Peek, J.M., Strand, E.K. 2006. Estimates of Elk Summer Range Nutritional Carrying Capacity Constrained by Probabilities of Habitat Selection. J. Wildl. Manag. 70: 283-294. 
Beschta, R.L. \& Ripple, W.J. 2009. Large predators and trophic cascades in terrestrial ecosystems of the western United States. Biol. Conserv. 142: 2401-2414.

Beschta, R.L. \& Ripple, W.J. 2010. Mexican wolves, elk, and aspen in Arizona: Is there a trophic cascade? For. Ecol. Manag. 260: 915-922.

Binkley, D. 2008. Age distribution of aspen in Rocky Mountain National Park, USA. For. Ecol. Manag. 255: 797-802.

Borkowski, J. 2004. Distribution and habitat use by red and roe deer following a large forest fire in South-western Poland. For. Ecol. Manag. 201: 287-293.

Bunnefeld, N., Linnell, J.D.C., Odden, J., van Duijn, M.A.J. \& Anderson, R. 2006. Risk taking by Eurasian lynx (Lynx lynx) in a human-dominated landscape: effects of sex and reproductive status. J. Zool. 270: 31-39.

Campbell, R.B. \& Bartos, D.L. 2001. Aspen ecosystems: objectives for sustaining biodiversity. In: Sheppard, W.D., Binkley, D., Bartos, D.L., Stohlgren, T.J. \& Eskew LG (eds.) Sustaining aspen in western landscapes: symposium proceedings, pp. 299-307. RMRS-P-18. USDA, Forest Service, Rocky Mountain Research Station, Fort Collins, CO,

DeByle, N.V. 1985. Wildlife. In: DeByle NV, Winokur R. P. (eds.) Aspen: ecology and management in the western United States, pp 135-152.RM-119. USDA, Forest Service, Rocky Mountain Forest and Range Experiment Station, Fort Collins, CO.

DeRose, R.J. \& Long, J.N. 2010. Regeneration response and seedling bank dynamics on a Dendroctonus rufipennis-killed Picea engelmannii landscape. J.Veg. Sci. 21: 377-387.

Di Orio, A.P., Callas, R. \& Schaefer, R.J. 2005. Forty-eight year decline and fragmentation of aspen (Populus tremuloides) in the South Warner Mountains of California. For. Ecol. Manag. 206: 307-313.

Edenius, L. \& Ericsson, G. 2007. Aspen demographics in relation to spatial context and ugulate browsing: Implications for conservation and forest management. Biol. Conserv. 135: 293-301.

Edenius, L., Ericsson, G., Kempe, G., Bergström. R. \& Danell, K. 2011. The effects of changing land use and browsing on aspen abundance and regeneration: a 50-year perspective from Sweden. J. Appl. Ecol. 48: 301-309.

Fortin, D., Beyer, H.L., Boyce, M.S., Smith, D.W., Duchesne, T. \& Mao, J,S, 2005. Wolves influence elk movements: behavior shapes a trophic cascade in Yellowstone National Park. Ecol. 86: 13201330.

Gill, R. 2006. The influence of large herbivores on tree recruitment and forest dynamics. In: Danell, K., Bergström, R., Duncan, P. \& Pastor, J. (eds.) Large Herbivore Ecology, Ecosystem Dynamics and Conservation, pp. 170-202. Cambridge University Press, Cambridge, UK.

Harniss, R.O. \& Harper, K.T. 1982. Tree dynamics in seral and stable aspen stands of central Utah. INTRP-297. USDA, Forest Service, Intermountain Forest and Range Experiment Station, Ogden, UT.

Jones, B.E., Burton, D. \& Tate, K.W. 2005. Effectiveness monitoring of aspen regeneration on managed rangelands. R5-EM-TP-004, USDA, Forest Service, Pacific Southwest Region, Vallejo, CA.

Kay, C.E. 2001. Long-term aspen exclosures in the Yellowstone Ecosystem. In: Sheppard, W.D., Binkley, D., Bartos, D.L., Stohlgren, T.J. \& Eskew, L.G. (eds.) Sustaining aspen in western landscapes: symposium proceedings, pp 225-240. RMRS-P-18. USDA, Forest Service, Rocky Mountain Research Station, Fort Collins, CO.

Kay, C.E. \& Bartos, D.L. 2000. Ungulate herbivory on Utah aspen: assessment of long-term exclosures. J. Range Manag. 53: 145-153.

Kota, A.M. \& Bartos, D.L. 2010. Evaluation of techniques to protect aspen suckers from ungulate browsing in the Black Hills. West. J. Appl. For. 25: 161-168.

Kouki, J., Arnold, K. \& Martikaninen, P. 2004. Long-term persistence of aspen - a key host for many threatened species - is endangered in old-growth conservation areas in Finland. J. Nat. Conserv. 12: $41-52$. 
560

561

562

563

564

565

566

567

568

569

570

571

572

573

574

575

576

Kuhn, T.J., Safford, H.D., Jones, B.E. \& Tate, K.W. 2011. Aspen (Populus tremuloides) stands and their contribution to plant diversity in a semiarid coniferous landscape. Plant Ecol. 212: 1451-1463.

Kulakowski, D., Veblen, T.T. \& Drinkwater, S. 2004. The persistence of quaking aspen (Populus tremuloides) in the Grand Mesa area, Colorado. Ecol. Appl. 14: 1603-1614.

Kurzel, B.P., Veblen, T.T. \& Kulakowski, D. 2007. A typology of stand structure and dynamics of Quaking aspen in northwestern Colorado. For. Ecol. Manag. 252: 176-190.

Landres, P.B., Morgan, P., Swanson, F.J. 1999. Overview of the use of natural variability concepts in managing ecological systems. Ecol. Appl. 9: 1179-1188.

Long, J.N. \& Mock, K.E. 2012. Changing perspectives on regeneration ecology and genetic diversity in western quaking aspen: implications for silviculture. Can. J. For. Res. 42: 2011-2021.

Manier, D.J. \& Laven, R.D. 2002. Changes in landscape patterns associated with the persistence of aspen (Populus tremuloides Michx.) on the western slope of the Rocky Mountains, Colorado. For. Ecol. Manag. 167: 263-284.

Martin, T.E. \& Maron, J.L. 2012. Climate impacts on bird and plant communities from altered animalplant interactions. Nat. Clim. Change 2: 195-200.

McCune, B., Grace, J.B. \& Urban, D.L. 2002. Analysis of ecological communities. MjM Software, Gleneden Beach, OR.

McCune, B. \& Mefford, M.J. 2006. PC-ORD: multivariate analysis of ecological data. [software] MjM Software, Gleneden Beach, OR.

Mittanck, C.M. 2012. Exploring a stable aspen niche within aspen-conifer forests of Utah. Masters Thesis. Department of Wildland Resources. Utah State University, Logan, UT.

Mock, K.E., Rowe, C.A., Hooten, M.B., Dewoody,J. \& Hipkins, V.D. 2008. Clonal dynamics in western North American aspen (Populus tremuloides). Mol. Ecol. 17: 4827-4844.

O'Brien, M., Rogers, P.C., Mueller, K., MacWhorter, R., Rowley, R., Hopkins, B., Christensen, B. \& Dremann, P. 2010. Guidelines for aspen restoration on the National Forests in Utah. Western Aspen Alliance, Utah State University, Logan, UT.

Olmsted, C.E. 1979. The ecology of aspen with reference to utilization by large herbivores in Rocky Mountain National Park. In: Boyce, M.S. \& Hayden Wing, L.D. (eds.) North American Elk: Ecology, Behavior, and Management, pp. 89-97. University of Wyoming, Laramie, WY.

Peck, J.E. 2010. Multivariate analysis of community ecologists: step-by-step using PC-ORD. MjM Sortware Design, Gleneden Beach, OR.

Rehfeldt, G.E., Ferguson, D.E. \& Crookston, N.L. 2009. Aspen, climate, and sudden decline in western USA. For. Ecol. Manag. 258: 2353-2364.

Rogers, P.C., Landh $\square$ usser, S.M., Pinno, B.D., \& Ryel, R.J. 2013. A Functional Framework for Improved Management of Western North American Aspen (Populus tremuloides Michx.) For. Sci. In press.

Rogers, P.C., Bartos, D.L. \& Ryel, R.J. 2011. Historical patterns in lichen communities of montane quaking aspen forests. In: Daniels, J.A. (eds.) Advances in Environmental Research, Vol. 15, pp. 33-64. Nova Science Publishers, Inc., Hauppauge, NY.

Rogers, P.C., Leffler, A.J. \& Ryel, R.J. 2010. Landscape assessment of a stable aspen community in southern Utah, USA. For. Ecol. Manag. 259: 487-495.

Rogers, P.C. \& Ryel, R.J. 2008. Lichen community change in response to succession in aspen forests of the Rocky Mountains, USA. For. Ecol. Manag. 256: 1760-1770.

Sankey, T.T. 2009. Regional assessment of aspen change and spatial variability on decadal time scales. Remote Sens. 1: 896-914.

Seager, S.T., Eisenberg, C., \& St. Clair, S.B. 2013. Patterns and consequences of ungulate herbivory on aspen in western North America. For. Ecol. Manag. In press. doi.org/10.1016/j.foreco.2013.02.017

Sexton, J.O., Ramsey, R.D. \& Bartos, D.L. 2006. Habitone analysis of quaking aspen in the Utah Book Cliffs: effects of site water demand and conifer cover. Ecol. Model. 198: 301-311. 
605

606

607

608

609

610

611

612
Shepperd, W., Rogers, P.C., Burton, D. \& Bartos, D.L. 2006. Ecology, management, and restoration of aspen in the Sierra Nevada. RMRS-GTR-178. USDA, Forest Service, Rocky Mountain Research Station, Fort Collins, CO.

Shinneman, D.J., Baker, W.L., Rogers, P.C. \& Kulakowski, D. 2013. Fire regimes of quaking aspen in the Mountain West. For. Ecol. Manag. In press. doi.org/10.1016/j.foreco.2012.11.032

Smart, J.C.R., Ward, A.I. \& White, P.C.L. 2004. Monitoring woodland deer populations in the UK: an imprecise science. Mamm. Rev. 34: 99-114.

Stritar, M.L., Schweitzer, J.A., Hart, S.C. \& Bailey, J.K. 2010. Introduced ungulate herbivore alters soil processes after fire. Biol. Invasions 12: 313-324.

Takatsuki, S, 2009. Effects of sika deer on veggetation in Japan: a review. Biol. Conserv. 142: 19221929.

Tanentzap, A.J., Burrows, L.E., Lee, W.G., Nugent, G., Maxwell, J.M. \& Coomes, D.A. 2009. Landscape-level vegetation recovery from herbivory: progress after four decades of invasive red deer control. J. Appl. Ecol. 46: 1064-1072.

Welsh, S.L., Atwood, N.D., Goodrich, S. \& Higgins, L.C. 1987. A Utah Flora. Great Basin Naturalist Memoir \#9, Brigham Young University Press, Provo, UT, US.

White, C.A., Olmsted, C.E. \& Kay, C.E. 1998. Aspen, elk, and fire in the Rocky Mountain national parks of North America. Wildl. Soc. Bull. 26: 449-462.

Worrall, J.J., Egeland, L., Eager, T., Mask, R.A., Johnson, E.W., Kemp, P.A. \& Shepperd, W.D. 2008. Rapid mortality of Populus tremuloides in southwestern Colorado, USA. For. Ecol. Manag. 255: 686-696.

Zegler, T.J., Moore, M.M., Fairweather, M.L., Ireland, K.B. \& Fule, P.Z. 2012. Populus tremuloides mortality near the southwestern edge of its range. For. Ecol. Manag. 282:196-207.

Zeigenfuss, L.C., Binkley, D., Tuskan, G.A., Romme, W.H., Yin, T., DiFazio, S. \& Singer, F.J. 2008. Aspen ecology in Rocky Mountain National Park: age distribution, genetics, and the effects of elk herbivory. Open File Rep. 2008-1337, USDI, Geological Survey, Reston, VA.

Zeveloff, S.I. \& Collett, F.R. 1988. Mammals of the Intermountain West. University of Utah Press, Salt Lake City, UT.

\section{Supplementary Materials}

Appendix S1: Photos depicting an exclosure limiting ungulate browsing in the study area.

S1a: Ungulate exclosure depicts regular recruitment within fenced area, Book Cliffs, Utah, USA.

S1b: Alternate view of S1a showing opposite side of ungulate exclosure, Book Cliffs, Utah, USA.

S1c: Close-up of corner posts of ungulate exclosure depicting $0.5 \mathrm{~m}$ gap at base that allows mule deer (Odocoileus hemionus) access, but not elk (Cervus elaphus) or cattle (Bos spp.), Book Cliffs, Utah, USA. 
Table 1: Ranking of stand condition based on visual estimates of overstorey, regeneration/recruitment, and browse of young aspen suckers. A stand must meet all the criteria for either "Good" or "Poor" condition, otherwise it is rated as moderate. "Mortality" is defined as standing dead mature trees. Browse includes branch tips, buds, and leaves missing, as well as presence of multi-stemmed ("bushy") aspen regeneration.

\begin{tabular}{lllll}
\hline Code & Descriptor & $\begin{array}{l}\text { Overstory } \\
\text { Mortality/disease }\end{array}$ & Vertical Stand Layers & Visible Browse Impacts \\
\hline $\mathbf{1}$ & Good & $\begin{array}{l}\text { Minimal overstorey } \\
\text { mortality and stem } \\
\text { disease present }(<5 \%)\end{array}$ & Several aspen layers $(\geq 3)$ & $\begin{array}{l}\text { Browsing impacts on } \\
\text { regeneration uncommon } \\
(<25 \%)\end{array}$ \\
$\mathbf{3}$ & Moderate & $\begin{array}{l}\text { Does not fit } 1 \text { or } 3 \\
\text { Overstorey mortality }\end{array}$ & Does not fit 1 or 3 & Does not fit 1 or 3 \\
Poor & $\begin{array}{l}\text { layering absent or minimal } \\
\text { common }(>25 \%)\end{array}$ & $\begin{array}{l}\text { Browsing impacts clearly } \\
\text { evident }(>50 \%) \text { on } \\
\text { regeneration. }\end{array}$
\end{tabular}


Table 2: Pearson's coefficients $(r)$ between environmental variables and primary ordination axes. The strongest response variables are in bold type where $r>0.5$ or $<-0.5$.

\begin{tabular}{lrr}
\hline & \multicolumn{2}{c}{$\boldsymbol{r}$ - value } \\
\cline { 2 - 3 } Variable name & Axis 1 & Axis 2 \\
\hline Elevation & 0.361 & 0.225 \\
Aspect & 0.137 & 0.083 \\
Slope & -0.169 & -0.271 \\
\% Polygon aspen & 0.334 & $\mathbf{0 . 5 1 5}$ \\
\% Polygon conifer & -0.244 & -0.488 \\
Aspen stand age & 0.051 & -0.112 \\
Total scat per ha & 0.206 & $\mathbf{0 . 9 4 3}$ \\
Cattle scat per ha & 0.011 & $\mathbf{0 . 5 5 1}$ \\
Elk scat per ha & 0.264 & $\mathbf{0 . 8 3 9}$ \\
Deer scat per ha & 0.043 & $\mathbf{0 . 5 7 0}$ \\
Aspen cover ha & 0.255 & 0.042 \\
Conifer cover ha & -0.101 & -0.282 \\
Sagebrush cover ha & 0.005 & 0.261 \\
Total tree cover ha & 0.165 & -0.145 \\
Aspen regeneration & $\mathbf{0 . 9 0 0}$ & 0.046 \\
\% regeneration browsed & 0.315 & 0.388 \\
Live aspen recruitment & 0.343 & -0.233 \\
Small tree BA & 0.236 & -0.147 \\
Medium tree BA & 0.213 & 0.033 \\
Large tree BA & 0.019 & 0.080 \\
Total aspen BA & 0.296 & -0.023 \\
Aspen trees per ha (TPH) & 0.339 & -0.091 \\
Recruitment as \% of TPH & 0.328 & -0.226 \\
\hline & & \\
\hline
\end{tabular}


616 Figure 1: Map of the study area shows all aspen locations as identified with aerial imagery and aspen 617 sample plot locations. Inset depicts the Book Cliffs study area within the Rocky Mountain region, USA.

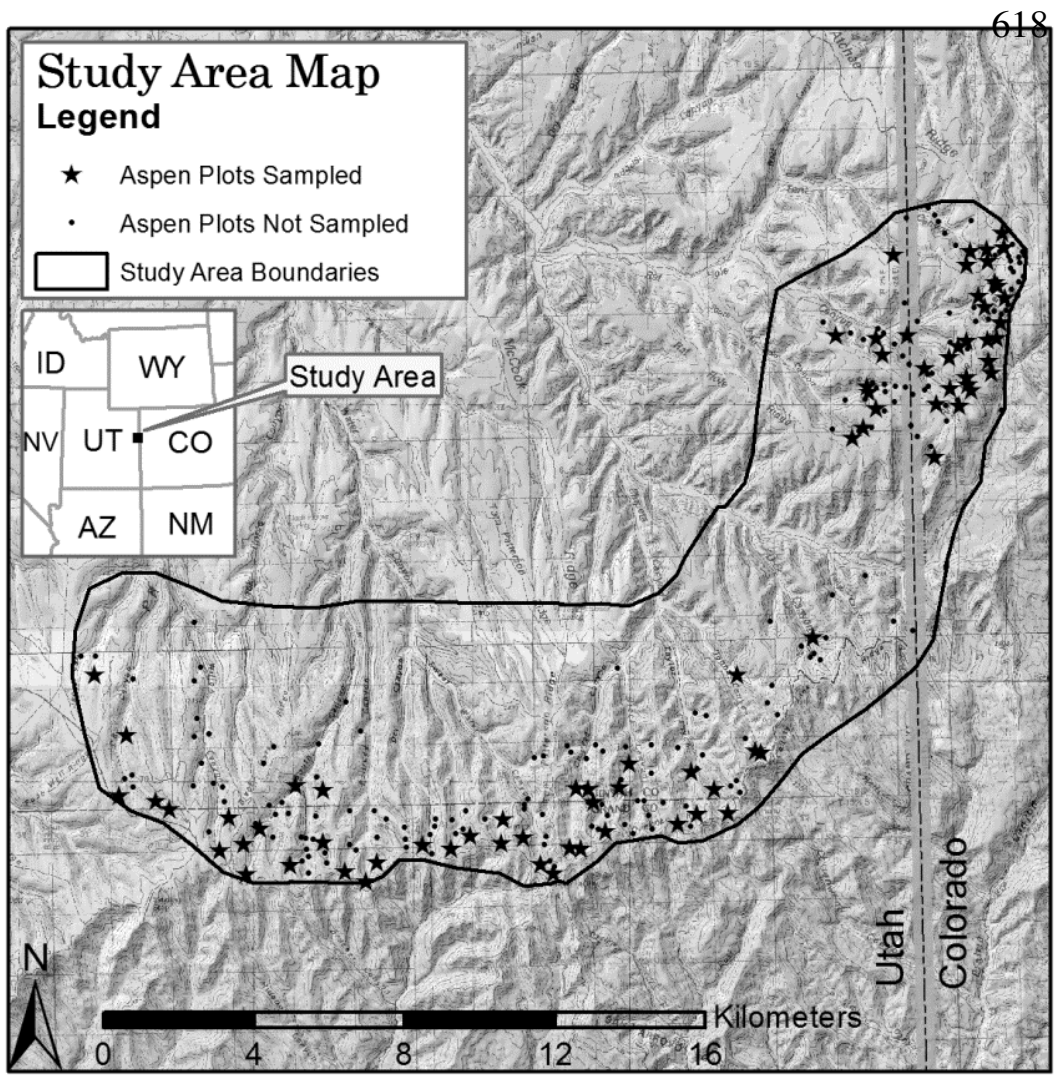


619

620

621

622

623

624

625

626

627
Figure 2: Wilcoxon-Mann-Whitney U test results displayed in box plots showing significant differences between seral and stable aspen types by plot-level indicators across the study landscape. Wilcoxon mean scores are shown on the Y-axis. Whiskers show minimum and maximum values, boxes represent $25-75 \%$ data ranges, horizontal lines within boxes are medians, and diamond symbols are means. Only results with $>95 \%$ confidence intervals are shown.
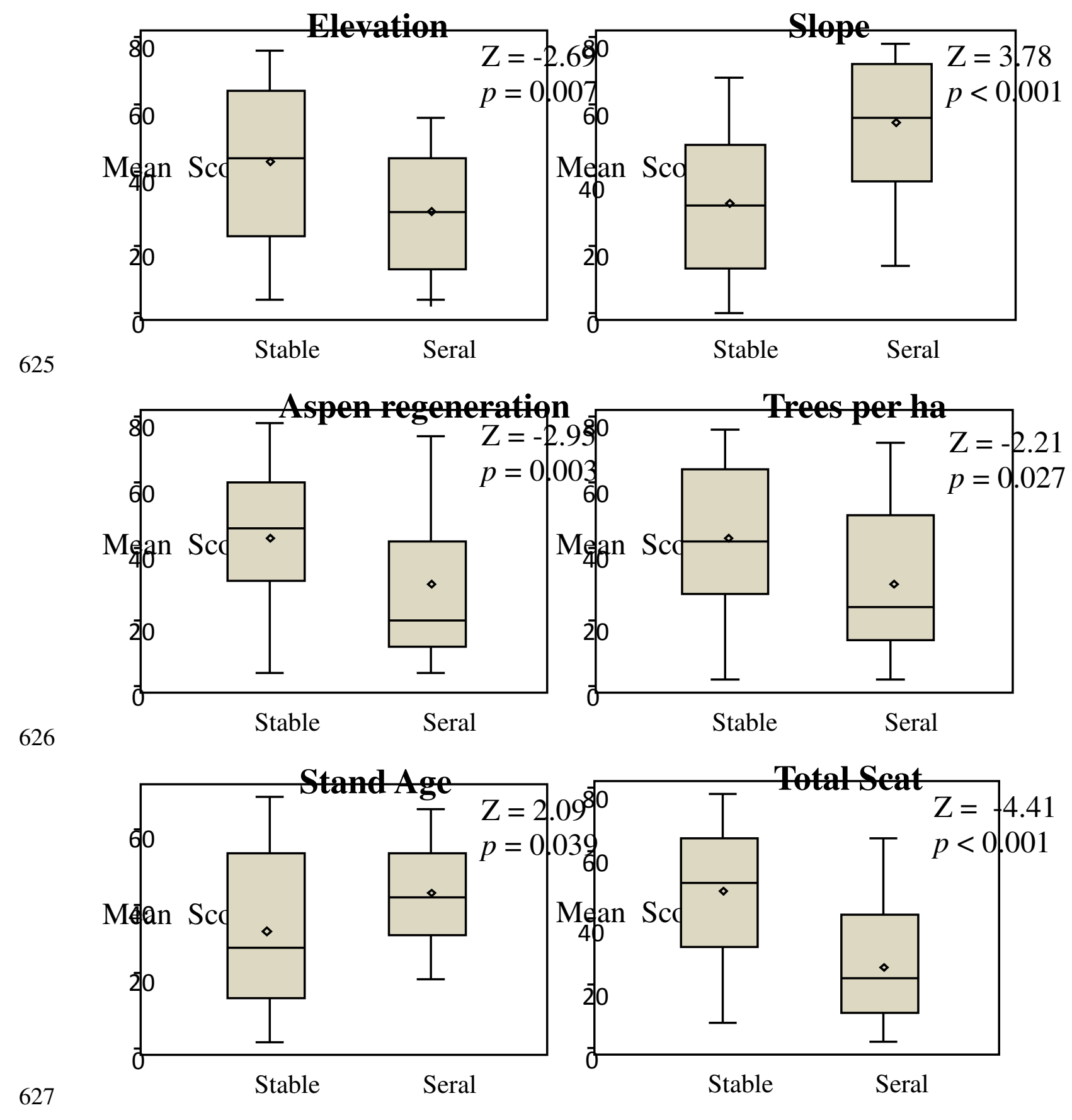


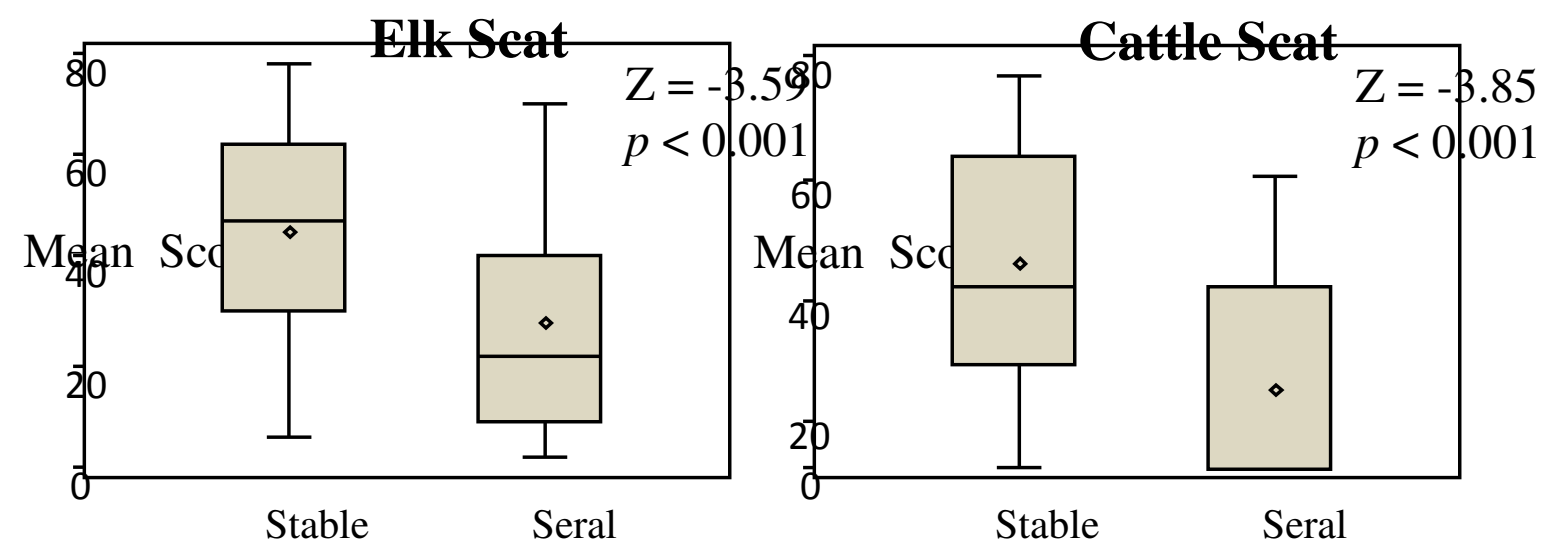


629 Figure 3: Histogram depicting the number of stable and seral aspen sample plots $(n=77)$ by the ratio of 630 recruitment stems ( $>2 \mathrm{~m}$ height) to overstorey aspen trees $\mathrm{ha}^{-1}$. Ninety-four percent of sample plots in 631 the study area had less than $50 \%$ of the overstorey stem count. The majority of aspen stands had zero 632 recruitment.

633

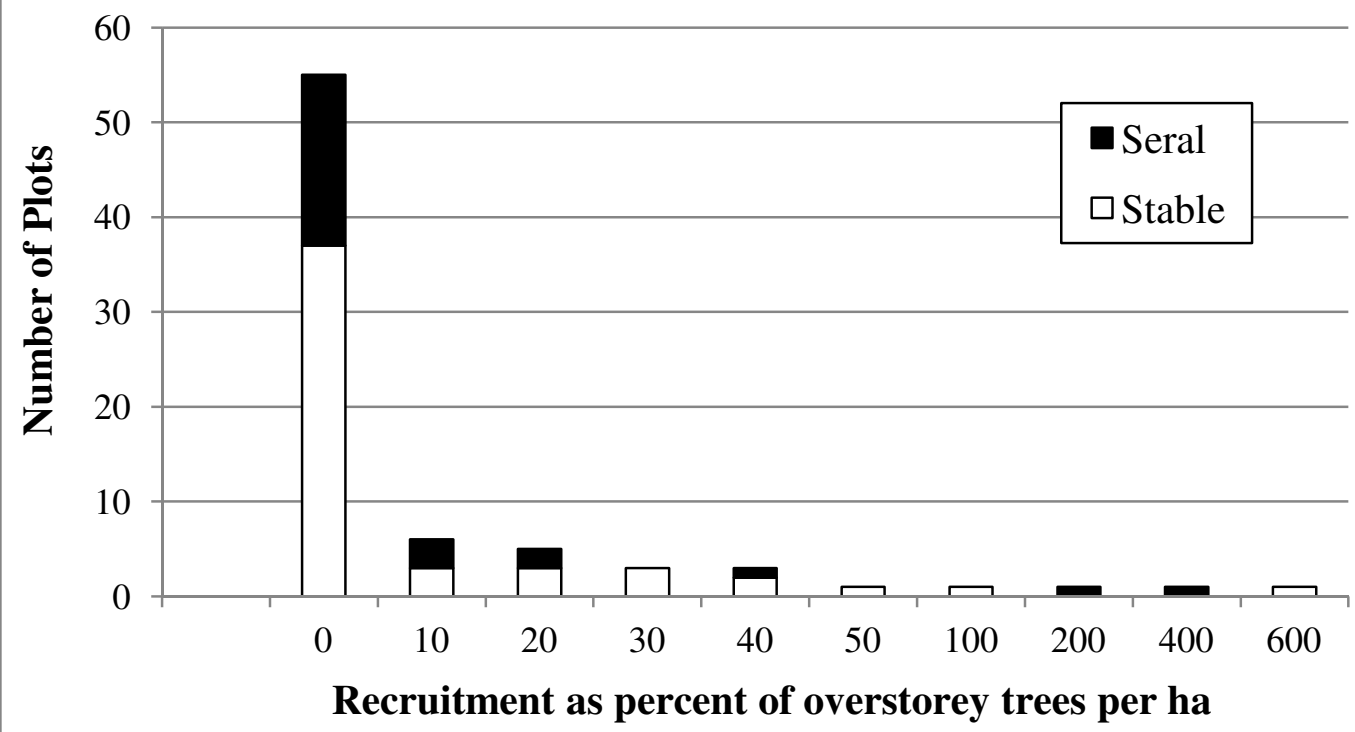


Figure 4: Kruskal-Wallace test results are displayed in box plots showing significant differences between aspen condition classes across the study landscape. We intentionally did not test variables directly related to condition class elements (Table 2) in an effort to independently assess the value of the rating system. Wilcoxon mean scores are shown on the $\mathrm{Y}$-axis. Whiskers show minimum and maximum values, boxes represent 25-75\% data ranges, horizontal lines within boxes are medians, and diamond symbols are means. Box plots display general trends between three classes; test results apply only to an overall group difference. Only results with $>95 \%$ confidence intervals are shown.

Elevation

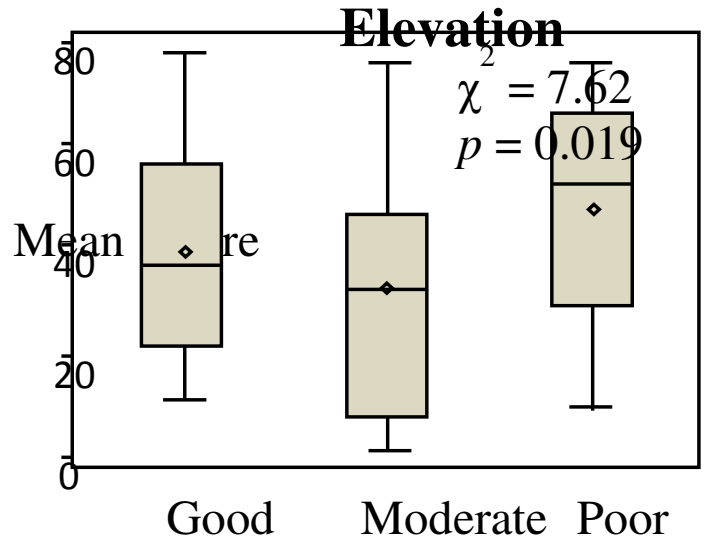

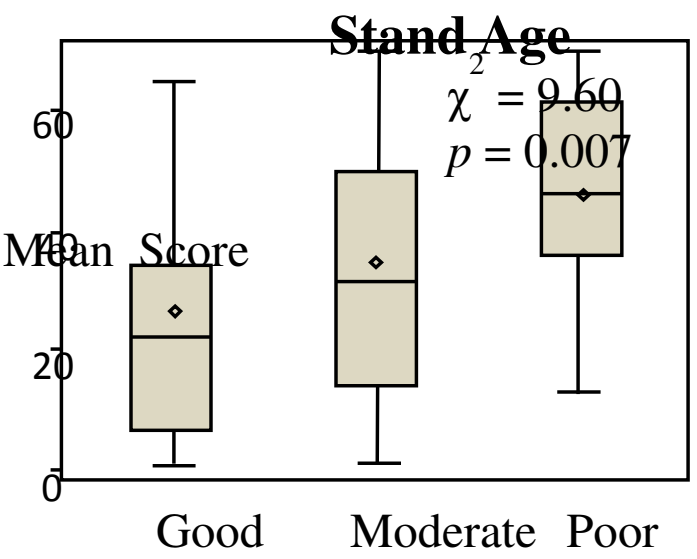
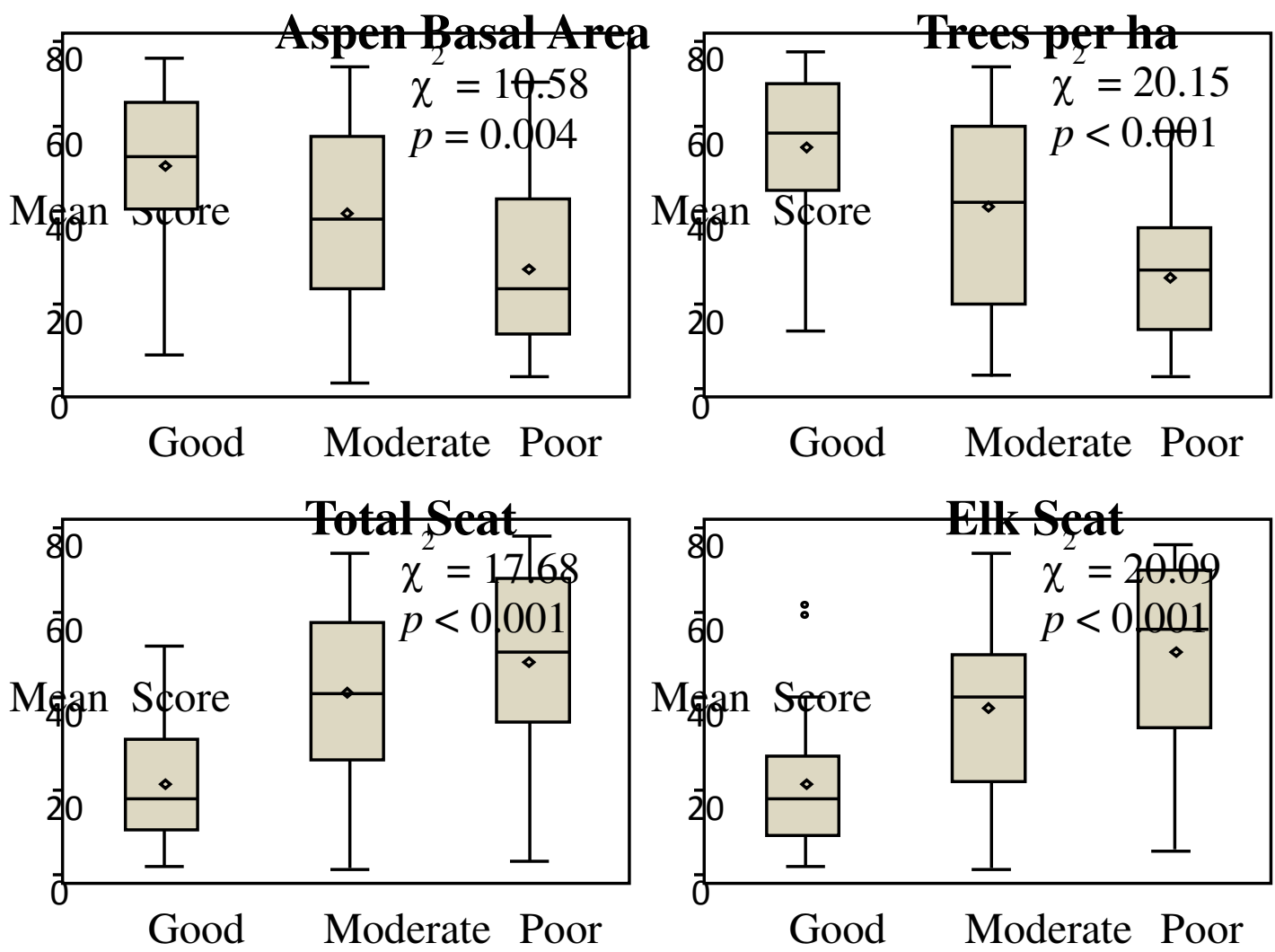
Figure 5: Nonmetric multidimensional scaling (NMS) results are shown in a joint plot which highlights

648 prominent indicators within the total Book Cliffs data set. Vectors with $>+/-0.5$ Pearson's coefficient $(r)$ value (Table 2) are displayed in relation to "plot space". The length of vectors corresponds to their $r$ value ("as_regen" = aspen regeneration; scat_ha = total scat; elk_ha, cow_ha, deer_ha = animal scat counts). Aspen stand condition ratings are superimposed within plot space to depict general relationships to the primary axes. Axis 1 displays general trends in regeneration, recruitment, aspen basal area, and aspen trees $\mathrm{ha}^{-1}$. Axis 2 corresponds to animal presence, prominently elk, polygon-level aspen cover (+) and conifer cover (-), and percent of regeneration browsed.

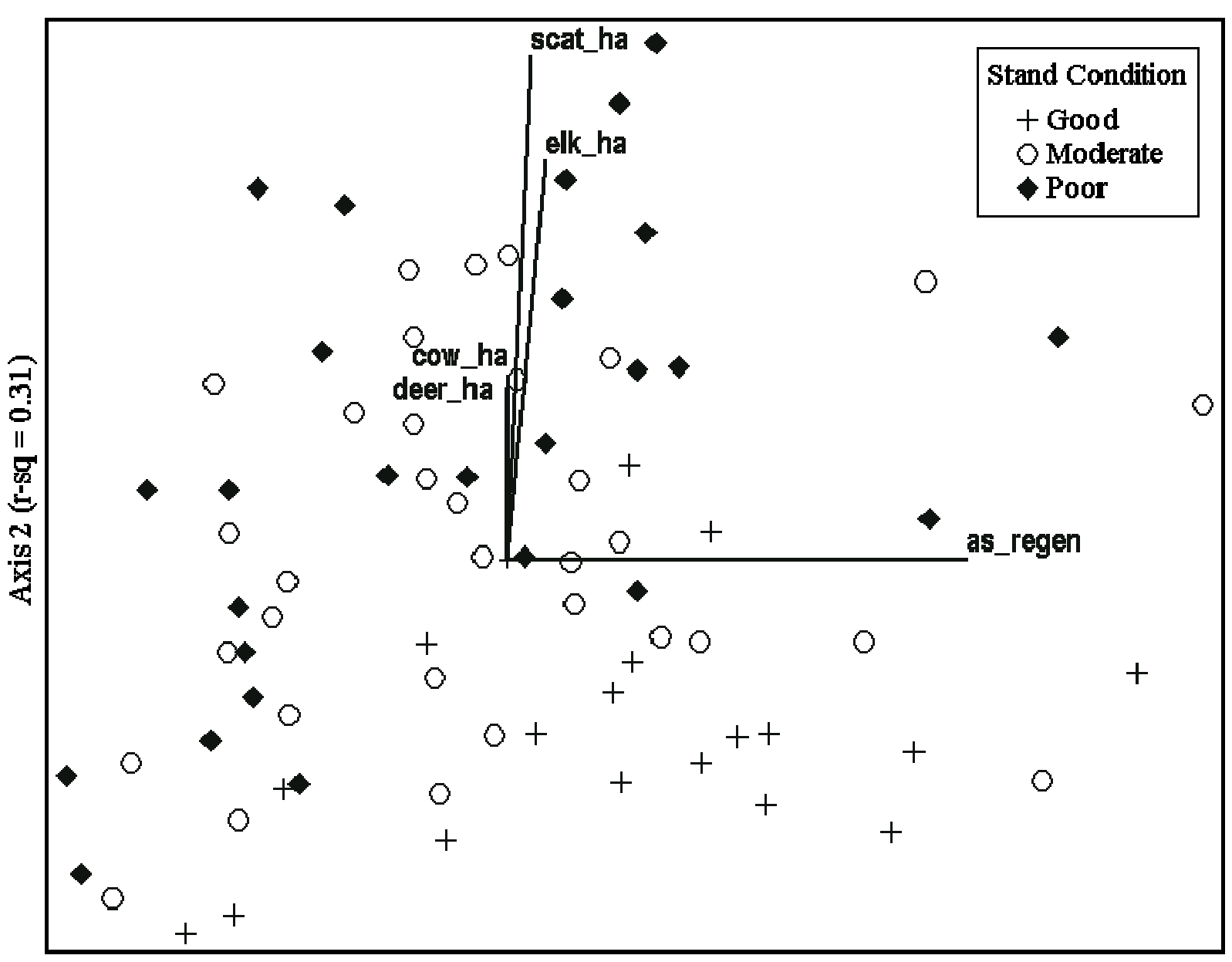

